\title{
A SECOND NOTE ON GESOMYRMEX
}

\section{By William MoRTON WheELER ${ }^{1}$}

On his recent return from a sojurn of several years in the Philippines, Dr. James W. Chapman generously gave me a considerable portion of a colony of Gesomyrmex which he had had under observation at his camp (alt. $1500 \mathrm{ft}$.) near Dumaguete. The specimens are of unusual interest because they comprise not only a complete series of the various worker forms and therefore confirm the conclusions recorded in my former paper $^{2}$ on the identity of the genera Gesomyrmex and Dimorphomyrmex, but also the mother queen of the colony and an adult male. In the paper cited I endeavored to ascertain the characters of this sex from a young pupa of the Javan G. kalshoveni Wheeler, but examination of the specimen from the Philippines proves that my inferences from pupal structure were inadequate. Comparison of Dr. Chapman's queen with the female of G. luzonensis Wheeler shows that whereas both belong to the same species, the former represents an undescribed variety. Since the Luzon form is known only from a female specimen I shall have to compare the workers of the new variety with those of the closely allied kalshoveni.

Gesomyrmex luzonensis var. chapmani var. nov.

Worker maxima.-Length 6.5-7 $\mathrm{mm}$.

Distinctly larger and more robust than the maxima of G. kalshoveni and of a deeper, more reddish yellow color, with a large spot on the ocellar region and the discal, or

${ }^{1}$ Contribution from the Entomological Laboratory of the Bussey Institution, Harvard University, No. 332.

${ }^{2}$ The Identity of the Ant Genera Gesomyrmex Mayr and Dimorphomyrmex, Ernest Andre'. Psyche 36, 1929, pp. 1-12, 1 fig. 

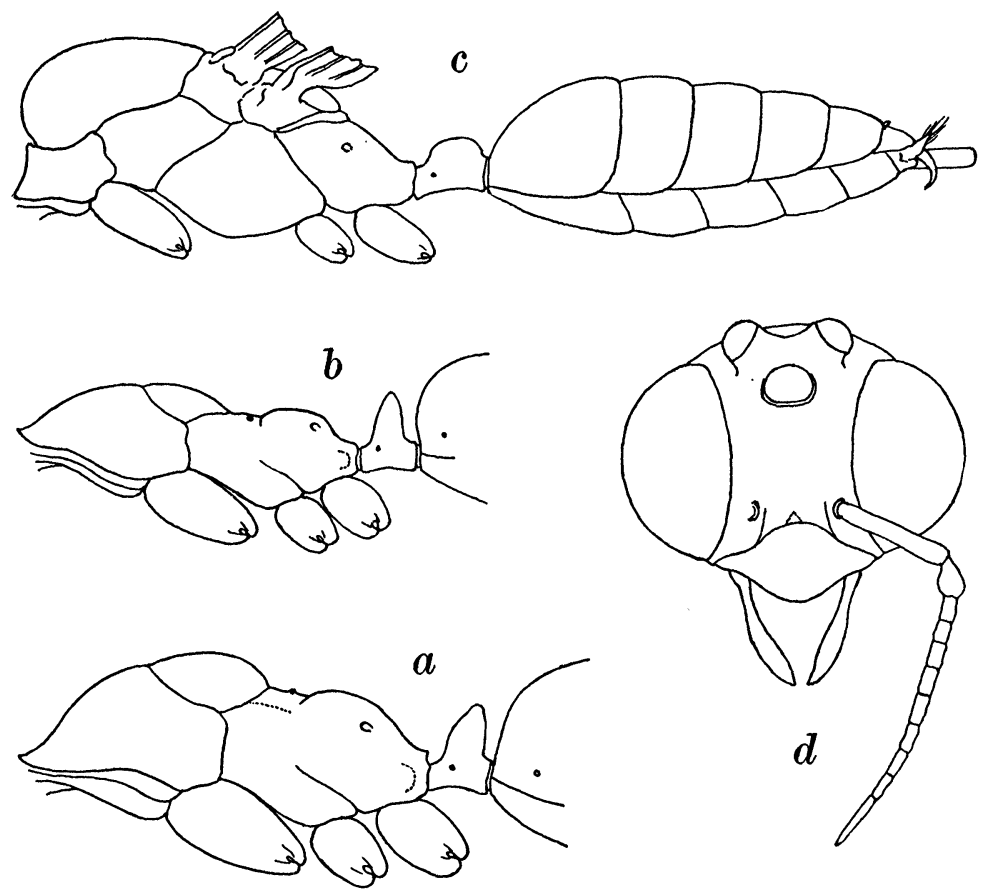

Fig. 1. Gesomyrmex luzonensis Wheeler, var. chapmani, var. nov. a, thorax and petiole of worker maxima in profile; $b$, same of worker minima; $c$, thorax and abdomen of male; $d$, head of male, dorsal view. 
central portion, of the pronotum dark brown. In some specimens the pleuræ and epinotum are reddish brown. Basal portions of the several gastric segments distinctly brownish. Mesonotum broader than long and much more convex than in kalshoveni. Petiole thicker above and less distinctly cuneate.

Worker media.-Length 4.5-6 $\mathrm{mm}$.

The larger specimens are as large as the maximæ of kalshoveni and differ from them only in their deeper yellow coloration, in having the spot on the vertex and the disc of the pronotum brown, though paler than in the maxima, and in the thicker and blunter petiolar node. In the smaller specimens the brown on the vertex and pronotum becomes fainter or disappears altogether.

Worker minima.-Length 2.5-3.5 mm.

Without dark markings and very similar to the minima of kalshoveni, but with the petiolar node distinctly thicker, less compressed above and therefore less cuneate in profile. The general yellow color of the body seems to be somewhat darker.

Female (deälated).-Length nearly $9 \mathrm{~mm}$.

Closely resembling the female of luzonensis in structure, pilosity and sculpture but differing in coloration. Paler and more ivory yellow, with a large rhomboidal spot on the middle of the head, covering more than the ocellar region, the wing insertions and the discal portions of the pronotum and epinotum dark castaneous brown. Dorsal surface of the same color, with the borders of the segments and a transverse band at the base of the first segment yellow.

Male.-Length $3.6 \mathrm{~mm}$.

Head small, including the large, convex eyes somewhat broader than long, broadly rounded behind, with extremely short cheeks. Ocelli large and prominent. Clypeus somewhat broader than long, convex in the middle, anteriorly 
produced as an entire, rounded lobe. Mandibles small, slender, edentate, subspatulate. Frontal area very small, triangular; antennæ short and slender, 11-jointed; scapes cylindrical, nearly as long as the four basal funicular joints together; first funicular joint swollen, ellipsoidal, one and one-half times as long as broad, remainder of funiculus tapering, joints 2-9 subequal, about one and one-half times as long as broad, terminal joint narrower, as long as the two penultimate joints together. Palpi long, maxillary pair 6-jointed, labial pair 4-jointed. Thorax broad and robust anteriorly, gradually narrowed behind, the pronotum short, with raised posterior border; mesonotum broader than long, broader than the head, strongly convex in front and somewhat overhanging the pronotum. Scutellum large, but not very convex. Epinotum small, narrower behind than in front, with rather flat, sloping dorsal surface, without differentiated base and declivity. Petiole resembling that of the female, nearly as long as broad, subrectangular from above, in profile with a thick, broadly and evenly rounded node, and feebly concave ventral surface. Gaster small, slender and elongate; cerci present; genital appendages exserted, the stipites small, spreading, subtriangular, acutely pointed and pilose, the volsellæ slender, falcate and deflected; sagittæ much larger, longer than broad, parallelsided, with truncated tips. Legs slender; hind femora slightly bowed; tarsal claws large.

Smooth and shining, very indistinctly and finely shagreened.

Pilosity white, delicate, almost absent on the head and thorax; erect and more abundant on the petiole and gaster, especially on the former; appendages with sparse, appressed pubescence; funiculi with short oblique hairs.

Sordid or brownish yellow; head dark brown; mesonotum and scutellum pale brown. Wings yellowish hyaline, with pale yellow veins and pale brown pterostigma.

Described from a series of 43 workers, a single female and single male, all from the same colony, captured by Dr. J. W. Chapman at Dumaguete, Negros Oriental, P. I.

A study of the male of this ant has led me to reverse my opinion in regard to the specimen which Mayr regarded as the male of his G. hoernesi from the Baltic Amber. Apart 
from its much greater size and its smaller mandibles, petiole and genital appendages, his specimen would, after all, seem to be a true male Gesomyrmex. The head, antennæ, thorax and wings are very much like the corresponding parts of the above-described male of chapmani, and the discrepancies in the other parts are perhaps attributable to defects in Mayr's figure. It is not so easy to make an accurate drawing of an insect embedded in a block of fossil resin as it is of one carded or pinned.

The specimens of the new variety were accompanied by Dr. Chapman's notes which are worth quoting, because they contain the first observations on the habits of Gesomyrmex. ${ }^{1}$

"May 11, 1924, at 8 A. M., while sitting on our azoteo, I noticed on the balustrade a honey-colored ant which arrested my attention by its peculiar jerky, zigzag gait and unusually large dark eyes. On capturing it I found it to be a small worker of Gesomyrmex! Then a few others were seen running about in the same place. I smeared some ripe banana in their path on the railing and found that they at once proceeded to gorge themselves with the juices. They eventually moved away and I followed them down a banister and along the sill to one of the large posts which serve as supports of the house. From this post they passed to a pole, which I had placed diagonally between two of the posts, to serve as a brace. They descended this for a foot or more and together entered a hole in its surface. There were other workers within the entrance but they could not be induced to come out. During the day several workers were seen to visit and feed on the banana. The last one retired to the nest at 5 P. M., apparently for the night.

"The pole containing the nest was about eight feet long and was two and one-half inches in diameter where the nest was situated. The entrance consisted of four small, slit-like holes, close together and resembling the orifices of beetle burrows. The pole had been cut about two weeks previously on the mountain side behind the house from a particular

${ }^{1}$ Dr. Chapman also sent me a series of drawings of the various worker castes of G. chapmani to illustrate the identity of Gesomyrmex and Dimorphomyrmex. I have not reproduced these drawings because they are so much like those in my paper on G. kalshoveni. 
tree, which was selected because it is known to be very resistant to the attacks of termites.

"May 12 and 13 the workers continued to visit the ripe banana in small numbers. I failed to excite the colony or to bring out any of the workers by pushing a straw into their nest entrances, by pounding on the pole or blowing into the cavity. On the evening of May 13 I decided to open the nest and therefore placed the pole on a large collecting canvas, filled the entrances with alcohol and carefully split the wood. The four entrances were seen to unite to form a single funnel-like passage, which grew narrower towards the end of the pole and opened into the middle of the main nest-cavity. This was about five inches long and one and a quarter inches from the surface. The two ends of the cavity were rounded out and the wood around the excavated pithy center had been gnawed away to form several irregular galleries. The colony had evidently been nesting in these cavities for some time. The wood was green and solid. There were about 150 adult workers, their queen, male and a number of eggs and larvæ."

These observations antedate and add materially to those of Dr. Kalshoven on G. kalshoveni cited in my first note. ${ }^{1}$

We may conclude from them that the colonies of Gesomyrmex are monometrotic, or possess a single mother queen, that they are not very populous and nest in sound wood. Like other lignicolous ants they probably take possession of the abandoned burrows of other insects and enlarge them by tunnelling in the wood as the colony grows. Dr. Chapman's observations show that the smaller and more numerous workers do most of the foraging, have a peculiar, jerky, zigzag gait and are very timid. He has not observed the guarding of the nest-entrances by the largest workers, though he seems to have seen workers stationed just within the entrance gallery.

${ }^{1}$ Note on Gesomyrmex. Psyche, 36, 1929, pp. 91, 92. 

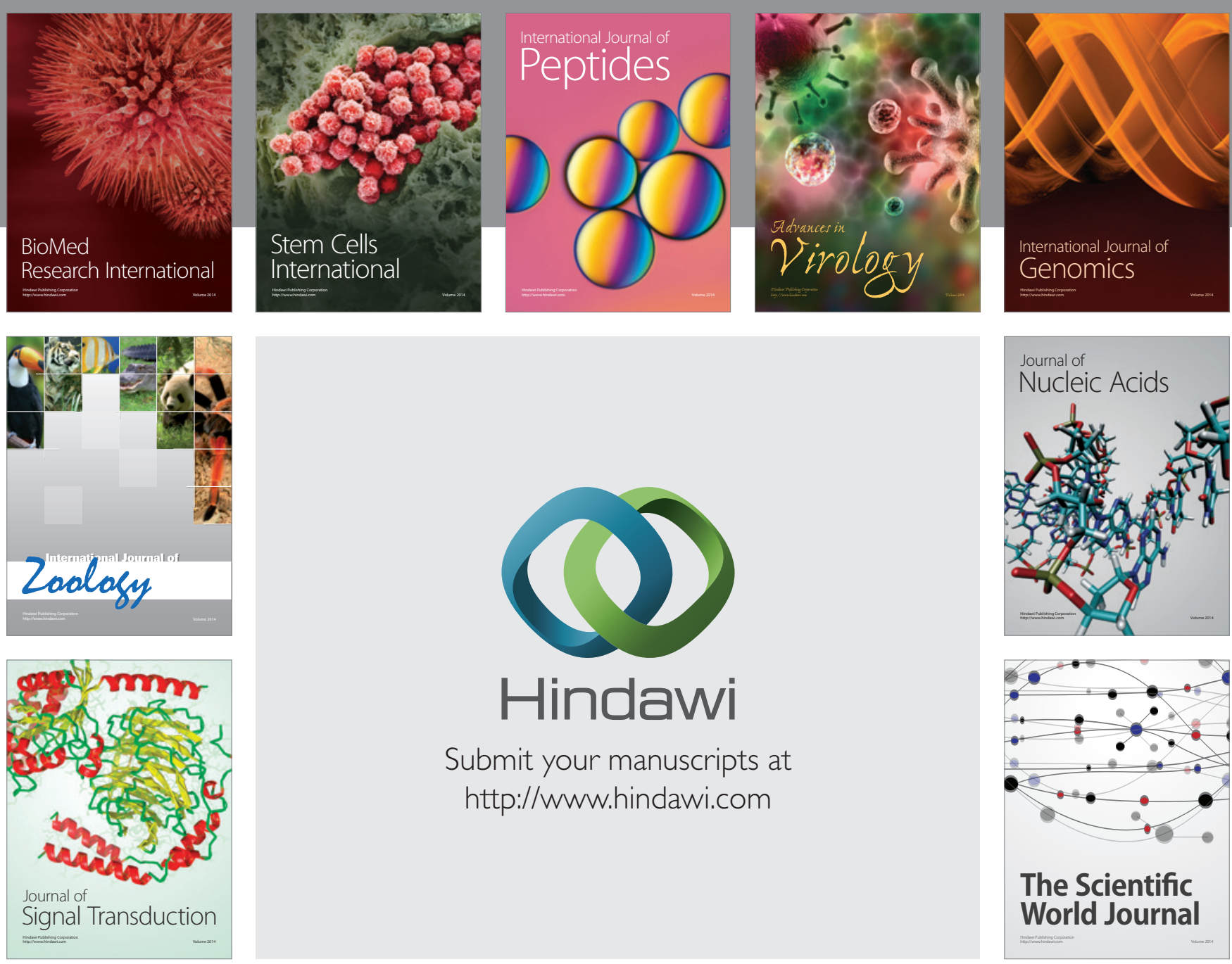

Submit your manuscripts at

http://www.hindawi.com
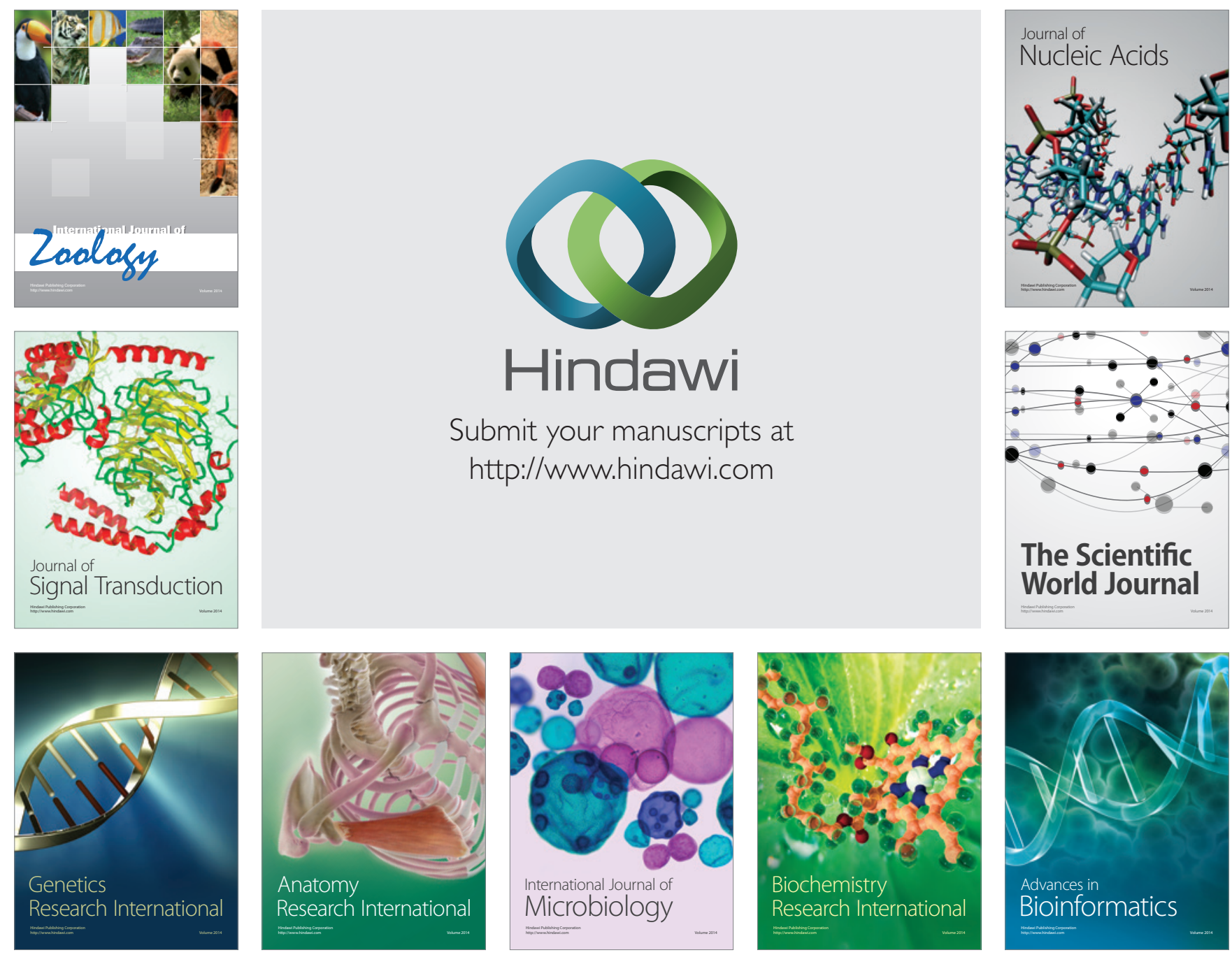

The Scientific World Journal
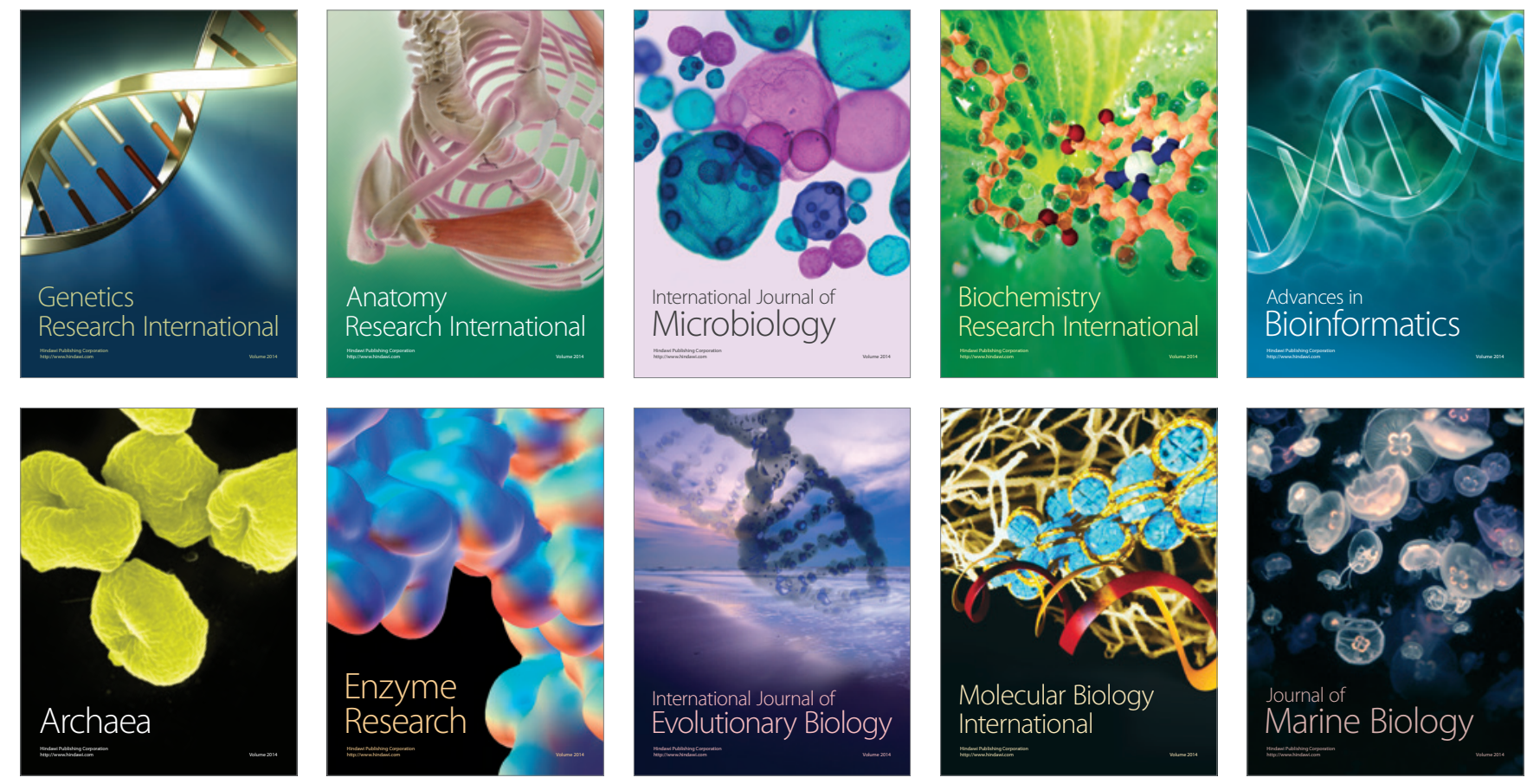